\title{
Inhibition of Müllerian Inhibiting Substance Secretion by FSH
}

\author{
BARRY B. BERCU, (") YASUHIDE MORIKAWA, IVOR M. D. JACKSON, AND PATRICIA K. \\ DONAHOE \\ Department of Pediatrics, Division of Pediatric Surgery, and the Pediatric Surgical Research Laboratory, \\ Massachusetts General Hospital, Boston, Massachusetts USA, and the Endocrine Division, New England Medical \\ Center, Tufts University School of Medicine, Boston, Massachusetts, and NICHD, National Institutes of Health, \\ Bethesda, Maryland, USA
}

\begin{abstract}
Summary
To evaluate the role of gonadotropins in the control of Müllerian Inhibiting Substance (MIS) secretion, pregnant rats were injected with rabbit antiserum against luteinizing hormone releasing hormone (LHRH), and their pups replaced with follicle stimulating hormone (FSH) and human chorionic gonadotropin (hCG). The LHRH antiserum (LHRH-AS) was given at 13 and 20 days of gestation. Control dams were injected with an equal volume of normal rabbit serum. The male pups from mothers treated with LHRH antiserum were given 5 daily s.c. injections of the FSH, hCG, or vehicle. The male pups from mothers treated with normal rabbit serum were given vehicle s.c. Testicular fragments of 6 day old pups born to mothers treated with LHRH antiserum during pregnancy showed an increase relative to controls in MIS activity in a graded organ culture bioassay system (grade $3.4 \pm 0.3$ vs. 2.3 $\pm 0.2)(P<0.01)$. FSH given to pups from mothers treated with LHRH antiserum reduced testicular MIS secretion compared to vehicle treated pups from the same mothers (grade $2.3 \pm 0.2 \mathrm{vs}$. $3.4 \pm 0.3)(P<0.01)$. Thus, postnatal injections of FSH after immunologic blockade of gonadotropins in utero reduced MIS activity of the testes to the same level found in testes of 6 day control pups (grade $2.3 \pm 0.2$ vs. $2.3 \pm 0.2$ ). In contrast, MIS activity remained high despite postnatal hCG injection in pups born to mothers given LHRH-AS (grade $3.4 \pm 0.4$ vs. $3.4 \pm 0.3$ ). These studies suggest that secretion of MIS is dependent on normal hypothalamic secretion of LHRH and may be inhibited by FSH.
\end{abstract}

\section{Speculation}

FSH inhibits MIS secretion.

MIS and testosterone are the principal hormones which govern the embryonic development of male genitalia. MIS, first described in mammals by Jost $(17,18)$ causes regression during midgestation of the Müllerian ducts of the male rat $(26,27)$. MIS is secreted by the testis from day 14 of fetal life to birth and, in progressively lesser concentrations, until day 21 of postnatal life. Testosterone induces development of the Wolffian duct into the vas deferens, seminal vesicle and epididymis (8); and its active metabolite, 5dihydrotestosterone, stimulates the urogenital sinus, genital tubercle, genital folds, and genital swellings to form prostate, glans, penis, and scrotum (8).

It is uncertain whether MIS is secreted autonomously or under extragonadal influences. Studies of the pituitary control of MIS have been inconclusive and conflicting. Maraud et al., $(23,24)$ demonstrated an increase in MIS activity of the 2-month-old chick testes after hypophysectomy at 1 month. However, GroenendijHuijbers and Burggraaff (12) noted a spontaneous return of MIS activity in the testes of the 4-month old chick. However, rats hypophysectomized at 20 -days of age failed "subsequently to demonstrate an elevation in testicular Müllerian inhibiting substance (11). Neither prolactin (Donahoe et al., unpublished data), nor placental fragments added to the in vitro culture influenced MIS activity.

Previously, we demonstrated that an antiserum to luteinizing hormone releasing hormone (LHRH-AS) blocked endogenous LHRH secretion in the neonatal rat (3-5). Both serum concentration and pituitary content of FSH and luteinizing hormone (LH) were reduced after injection of the LHRH antiserum $(2,19)$. Furthermore, an increase in MIS occurred after injection of LHRH antiserum, which suggested that FSH and/or LH inhibited MIS secretion from the testes (6).

In this study, pregnant rats were treated with LHRH antiserum and their male pups treated postnatally with FSH or hCG in order to determine which of the pituitary gonadotropins influenced MIS secretion.

\section{MATERIALS AND METHODS}

ANIMALS

Adult rats were obtained from Holtzman Laboratories. Females in estrus had been caged with males overnight and those with sperm positive vaginal smears on the next morning were used for study. That morning was recorded as day $1 / 2$ of pregnancy. The animals were housed in a temperature-controlled room $\left(25^{\circ} \pm 1^{\circ}\right)$ with a daily lighting schedule of $14 \mathrm{hr}$ of light and $10 \mathrm{hr}$ of darkness, and with free access to Purina rat chow and tap water.

\section{BIOASSAY}

The presence of MIS was assayed by a graded organ culture method (9). The urogenital ridge from $14 \frac{1}{1}$ day female fetuses containing Wolffian and Müllerian ducts were placed on an agar coated stainless steel grid of a Falcon 3010 organ culture dish. Testicular tissue to be assayed, 1-2 mm fragments, were placed adjacent to the ducts. Incubations were performed over wells containing $2 \mathrm{ml}$ of media [(CMRL, 10\% fetal calf serum, 200 units penicillin and $200 \mathrm{mcg}$ streptomycin) (Gibco)] at $37^{\circ}$ for $72 \mathrm{hr}$ in a humidified atmosphere of $95 \%$ air and $5 \% \mathrm{CO}_{2}$. Specimens were then fixed in buffered formalin dehydrated in an alcohol series, cleared in xylene, and embedded in paraffin. The cranial end of the duct was cut in serial crosssections and stained with hematoxylin and eosin. Multiple sections were studied by light microscopy and regression of the duct graded on a scale of $0-5$. Five slides with 6-10 sections per slide were presented blindly to 2 independent experienced observers, and the mean grade of their observations was recorded.

\section{LHRH-ANTISERUM (LHRH-AS)}

Antiserum to LHRH was generated in rabbits by repeated intradermal/subcutaneous injections of synthetic LHRH conju- 
gated to bovine thyroglobulin by bisdiazotized benzidine (Jackson, unpublished data). This technique was similar to that used to generate antibodies to thyrotropin releasing hormone (15). For the initial injection, the complex was emulsified in Freund's complete adjuvant; subsequent injections used incomplete adjuvant. The LHRH antiserum showed no crossreactivity with deamido-LHRH, thyrotropin releasing hormone, somatostatin, vasopressin, triodothyronine, thyroxine, or angiotensin I or II. The antibody reacted with C-terminal nonapeptide, to pentapeptide fragments of $\mathrm{LHRH}$, but not significantly with $\mathrm{N}$-terminal fragments. A 1:280,000 dilution of LHRH antiserum bound $45 \%$ of labeled LHRH under the conditions of our radioimmunoassay (Jackson et al., unpublished data).

\section{GONADOTROPINS}

FSH was obtained from the NIAMDD, NIH Rat Pituitary Hormone distribution program (NIAMDD Rat FSH-RP-1). The biologic potency obtained from the insert was as follows: FSH, $2.1 \times$ NIH-FSH-S1 by hCG augmentation assay (29); LH, 0.02 $\times$ NIH-LH-S1 by ovarian ascorbic acid depletion (OAAD) assay (28); and TSH, 0.3 USP (bovine) units/mg by McKenzie assay (25). The biologic equivalent for NIH-FSH-S1 was $50 \mathrm{IU} / \mathrm{mg}$ by hCG augmentation assay (Second International Reference Preparation) (1). Because FSH is crosscontaminated with $\mathrm{LH}$, the following biologic potencies can be expected: FSH-RP-1 has 105 IU FSH and $11.5 \mathrm{IU} \mathrm{LH/mg.} \mathrm{From} \mathrm{Sigma,} \mathrm{hCG} \mathrm{was} \mathrm{obtained,}$ and its biological potency determined with the U.S.P. chorionic gonadotropin reference standard. In order to be certain that the doses of each hormone (20-22) were greater than previously reported for biological replacement, $100 \mathrm{mIU}$ FSH and 5 IU hCG were used. Both solutions were diluted in sterile water and administered in $0.16 \mathrm{ml}$ volume.

The vehicle for the control treatment was sterile water. Intermediate doses of FSH (20 and $60 \mathrm{mI}$.U.) were given to additional groups of male pups in the same volume.
EXPERIMENTAL PROTOCOL (FIG. 1)

Twenty 13 day old pregnant rats were given $1 \mathrm{ml}$ of LHRH antiserum ip, and another eight rats were treated with an equal volume of normal rabbit serum. On the 20th day of pregnancy, the females were again injected ip with another $1 \mathrm{ml}$ of LHRH antiserum or normal rabbit serum. After delivery, the males were carefully marked as LHRH antiserum or control pups, then were randomly assigned to six other dams who delivered the same day. Each new mother was assigned randomly coded pups from the

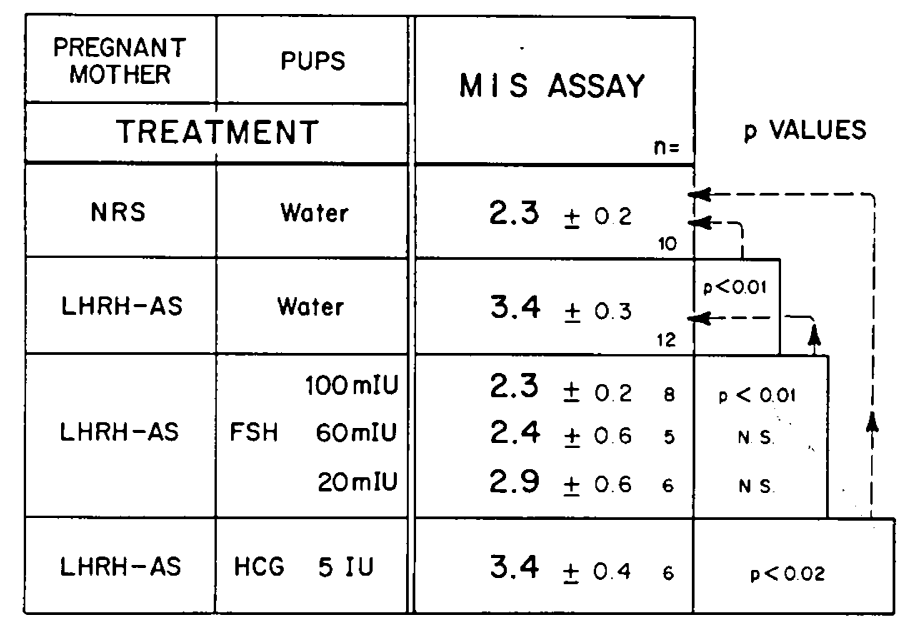

Fig. 2. MIS activity (mean) of testes from 6 day old pups whose mothers were treated with $1 \mathrm{ml}$ LHRH-AS or normal rabbit serum (NRS). Pups from LHRH-AS treated mothers were given: 1) 100 mI.U. FSH, 2) $60 \mathrm{ml} . U$. FSH, 3) $20 \mathrm{ml} . U$. FSH, 4) 5 I.U. hCG, and 5) water (postnatal control) daily s.c. for 5 days. Pups from NRS treated mother (pregnancy control) were given an equal volume of water. The means $\pm S E$ of the graded organ culture assay are compared.
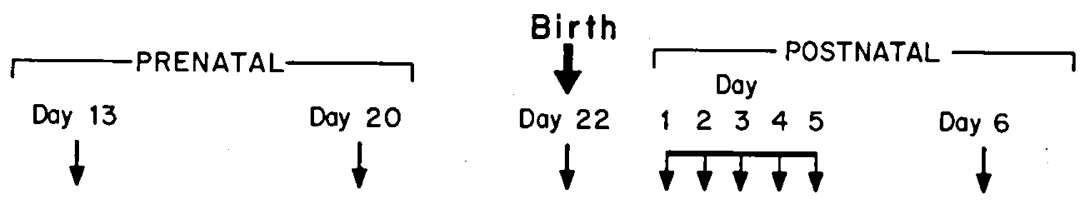

\section{LHRH ANTISERUM GROUP}

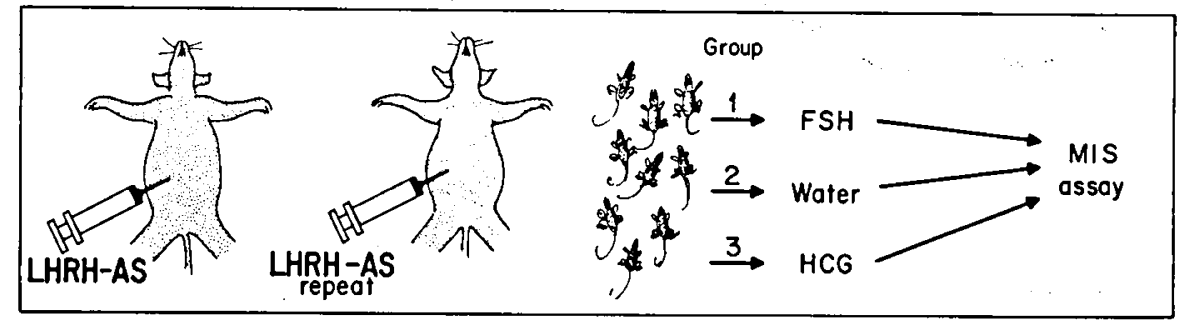

NORMAL RABBIT SERUM GROUP

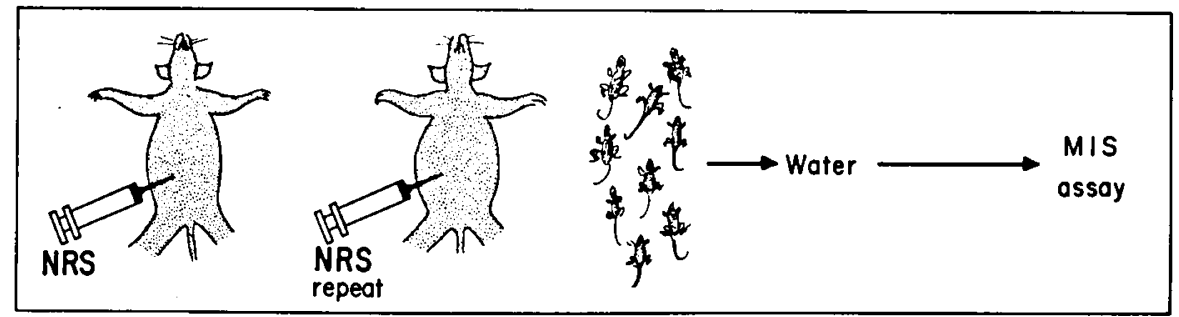

Fig. 1. Schematic representation of experimental protocol. LHRH-AS, $1 \mathrm{ml}$, or normal rabbit serum (NRS) (pregnancy control) was injected into pregnant dams at gestational ages 13 and 20 days. After birth, pups from LHRH-AS treated mothers received one of the following regimens s.c. daily for 5 days: 1) $100 \mathrm{mI} . U$. FSH, 2) $60 \mathrm{mI} . \mathrm{U}$. FSH, 3) $20 \mathrm{mI} . \mathrm{U}$. FSH, 4) 5 I.U. hCG, and 5) water (postnatal control); pups from NRS treated mothers received 6) water. Testis from 6-day old pups were assayed for MIS activity. 

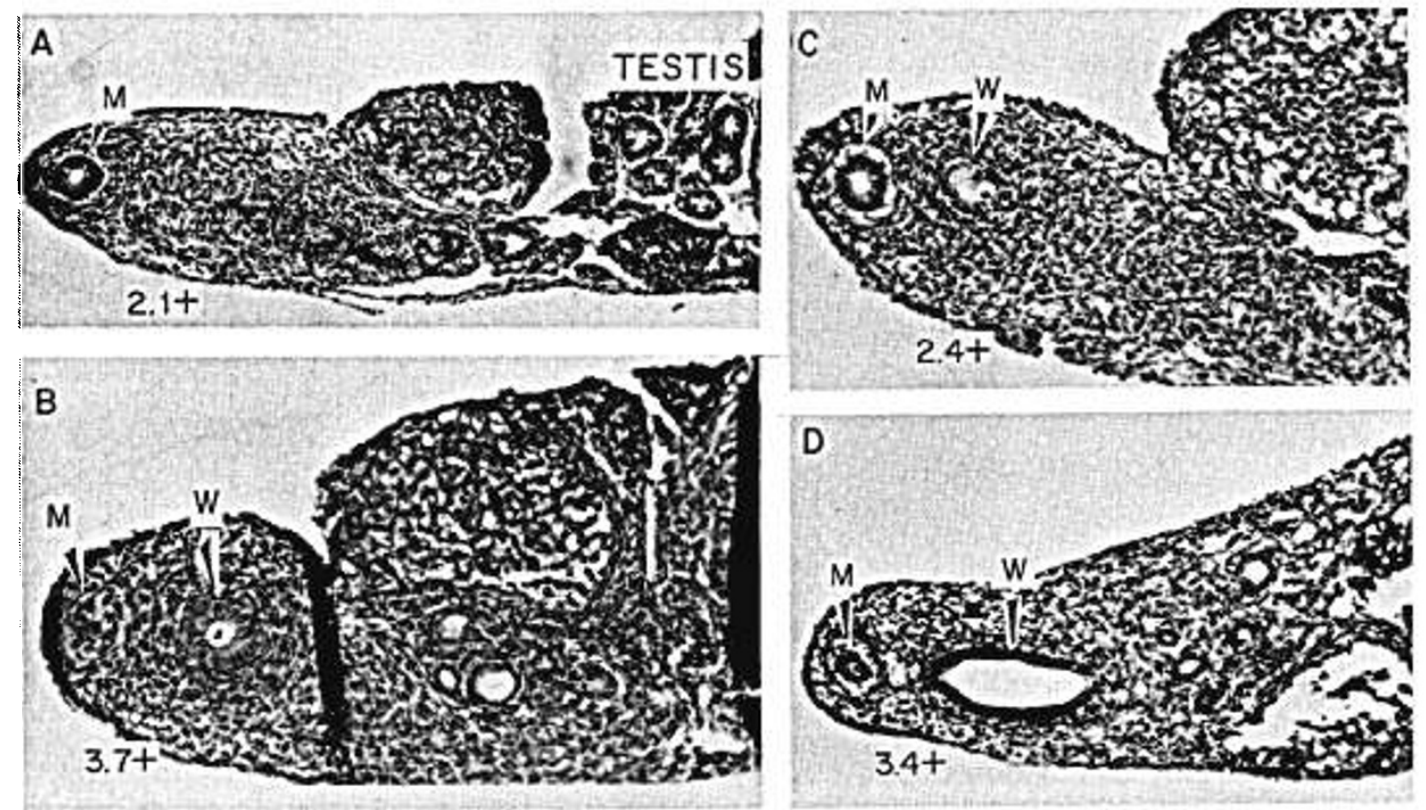

Fig. 3. Müllerian duct (M) regression in the 141/2 day female rat embryo urogenital ridge caused by testes from 6 day old male rats after 3 days in organ culture. $A$ ) Testis of rat born to a dam treated with normal rabbit serum (pregnancy control) and after birth, injected with water for 5 days ( 2.1 + regression). B) Testis of a newborn rat treated daily for 5 days with water born to a mother treated with LHRH-AS (postnatal control) (grade $3.7+$ regression). C) Pups in this group were given $100 \mathrm{mI}$.U. FSH after the pregnant dams were injected with LHRH-AS and their testes assayed for regression of Müllerian ducts $(2.4+)$. D) Pups in this group were given 5 I.U. hCG after the mother was injected with LHRH-AS and their testes assayed (3.4 + regression). ( $M)$ Müllerian duct, $(W)$ Wolffian duct.

following groups: pups from LHRH antiserum treated mothers which were subsequently given one of the following treatments, 1) 100 mI.U. FSH; 2) 60 mI.U. FSH; 3) 20 mI.U. FSH; 4) 5 I.U. hCG; and 5) water (postnatal control); pups from mothers treated with normal rabbit serum which were given 6) water (pregnancy control). All injections were given daily s.c. for the first 5 days of postnatal life. Those pups which receive vehicle after LHRH-AS will be defined as postnatal controls and those pups which receive vehicle after normal rabbit serum will be called pregnancy controls.

Tests from pups 6 days of age, were studied for MIS activity because of our previous observation that maternal treatment with LHRH antiserum resulted in the largest increase in MIS secretion relative to controls at this time. The animals were weighed and then decapitated. One testis was removed for MIS assay. Group comparisons were analyzed by unpaired $t$ tests. All data are presented as mean $\pm \mathrm{SE}$. In addition, the Wilcoxon rank-order test confirmed the statistical significance obtained with the student $t$ test.

\section{RESULTS}

\section{MÜLLERIAN INHIBITING SUBSTANCE ACTIVITY (FIG. 2 AND 3)}

Organ culture from testes of 6-day old pups treated from birth with vehicle showed higher MIS activity (grade $3.4 \pm 0.3$ ) if the dam had received LHRH antiserum at 13 and 20 days gestational age as opposed to normal rabbit serum (pregnancy control) (grade $2.3 \pm 0.2)(P<0.01)$. FSH $(100 \mathrm{mIU})$ given after birth to pups from mothers treated with LHRH antiserum reduced MIS secretion (grade $2.3 \pm 0.2 v s .3 .4 \pm 0.3)(P<0.01)$. These FSH treated pups from LHRH antiserum treated mothers had MIS activity similar to that of control pups from mothers treated with normal rabbit serum (grade $2.3 \pm 0.2$ vs. $2.3 \pm 0.2$ ). Pups from mothers treated with LHRH antiserum were given hCG; this failed to alter the increased testicular MIS activity resulting from the LHRH antiserum treatment of their dams (grade $3.4 \pm 0.4$ vs. $3.4 \pm 0.3$ ). Body weights in all groups did not differ, inferring that general health was unaltered.

\section{DISCUSSION}

The antiserum to LHRH used here has been shown previously to depress serum testosterone transiently in adult rats (3-5). Treatment of pregnant dams with LHRH-AS results in male pups with smaller than normal testes and external genitalia (6). We suggested that the LHRH antibody crossed the maternal-placental barrier and inhibited secretion of the fetal gonadotropins. The present study confirms our previous observation that this apparent inhibition of endogenous gonadotropins results in increased testicular MIS activity (6). Additionally, the present experimental data support our earlier speculation that FSH might inhibit MIS secretion. This was based on the knowledge that FSH controls certain functions of the Sertoli cell (13) and on the evidence that the Sertoli cell is the source of MIS $(7,16)$. Furthermore, the high serum FSH levels in late fetal and early postnatal life may account for the decreasing MIS during this period. The data clearly indicate that $\mathrm{hCG}$ and presumably $\mathrm{LH}$ do not restore the inhibitory effect seen with FSH after immunologic blockade with LHRH antiserum. The increasing inhibition of MIS activity with higher doses of FSH suggests a dose response, however the graded inhibition by lower FSH doses, although suggestive, is not statistically significant. This may be due to a small sampling and/or intraassay variation attributable to biologic assays in general. The gonadotropins in the fetal calf serum (14) used in the organ culture MIS assay should not interfere with the results because they are present in both treatment and control groups equally.

This study indicates that MIS secretion may be dependent on hypothalamic function through LHRH regulation of FSH release.

\section{REFERENCES AND NOTES}

I. Albert, A.: Editorial: Bioassay and radioimmunoassay of human gonadotropins. J. Clin. Endo. and Metab. 28: 1683 (1968).

2. Arimura, A. Shino, M. De La Cruz, K. G., Rennels, E. G., and Schally, A. V. Effect of active and passive immunization with luteinizing hormone releasing hormone and follicle-stimulating hormone levels and the ultrastructure of the pituitary gonadotrophs in castrated male rats. Endocrinology 99: 291 (1976)

3. Bercu, B. B., Jackson, I. M. D., Safaii, H., and Reichlin, S.: Testicular development requires luteinizing hormone releasing hormone (LRH) from birth. Evidence from studies of immunological blockade of endogenous LRH in the rat. 5th International Congress of Endocrinology, Hamburg, Germany (1976). 
4. Bercu, B. B., Jackson, I. M. D., Safaii, H., and Reichlin, S.: Permanent impairment of testicular development after transient immunological blockade of endogenous LHRH in the neonatal rat. Endocrinology 101: 1871 (1977).

5. Bercu, B. B., Jackson, I. M. D., Safaii, H., Sawin, C. T., and Reichlin, S.: The development of the pituitary gonadal azis in the male rat requires the luteinizing hormone releasing hormone (LRH) decapeptide from birth. Endocrine Society Meeting, San Francisco, Abstract No. 365, p. 239 (1976).

6. Bercu, B. B., Morikawa, Y., Jackson, I. M. D., and Donahoe, P. K.: Increased secretion of Müllerian inhibiting substance after immunological blockade of endogenous luteinizing hormone releasing hormone in the rat. Pediatr. Res. 12: 13. (1978).

7. Blanchard, M. G., and Josso, N.: Source of the anti mullerian hormone synthesized by the fetal testis: Müllerian inhibiting activity of fetal bovine sertoli cells in tissue culture. Pediatr. Res. S: 968 (1974).

8. Donahoe, P. K., and Hendren, W. H.: Evaluation of the newborn with ambiguous genitalia. Pediatr. Clin. N. Am., 23: 361 (1976).

9. Donahoe, P. K., Ito, Y., and Hendren, W. H.: A graded organ culture assay for the detection of Müllerian Inhibiting Substance. J. Surg. Res., 23: 141 (1977)

10. Donahoe, P. K., Ito, Y., Price, J., Hendren, W.: Müllerian Inhibiting Substance activity in bovine fetal, newborn, and prepubertal testes. Biol. Reprod., 16: 238 (1977).

11. Donahoe, P. K., Ito, Y., Marfatia, S., and Hendren, W. H.: The production of Müllerian inhibiting substance by the fetal, neonatal, and adult rat. Biol. Reprod., 15: 329 (1976).

12. Groenendijik-Huijbers, M., and Burggraaff, J.: Experimental studies on capability of embryonic and young chicken testes to regress embryonic chick oviducts. Anat. Anz. Bd., 135: 43 (1974).

13. Hansson, V., Ritzen, E. M., Granch, F. S., and Mayfeh, S. H.: Androgen transport and receptor mechanisms in testis and epididymis, In: Hamilton, D. W., and Greep, R.: Handbook of Physiology, Sect. 7, Endocrinology vol. V., Male reproductive system, 173 (American Physiological Society, Washington, 1975).

14. Honn, K. V., Singley, J. A., Chavin, W.: Fetal bovine serum; a multivariate standard. Proc. Soc. Exp. Biol. Med., 149: 344 (1975).

15. Jackson, I. M. D., and Reichlin, S.: Thyrotropin releasing hormone (TRH): distribtuion in hypothalamic and extrahypothalamic brain tissue to mammalian and submammalian chordates. Endocrinology, 95: 854 (1974).

16. Josso, N.: In vivo synthesis of müllerian inhibiting hormone by seminiferous tubules isolated from the calf fetal testis. Endocrinology, 93: 829 (1973).

17. Jost, A.: Sur la differentiation sexuelle de l'embryon de lapin remarque au sujet de certaines operations chirugical. C. R. Biol., 140: 460 (1946).

18. Jost, A.: Sur les derives mulleriens de l'embryons de lapin des deux sexes castres a 21 jours. C. R. Soc. Biol., 141: 135 (1947).

19. Koch, Y., Chobsieng, P., Zor, U., Fridkin, M., and Lindner, H.: Production and characterization of an antiserum to synthetic gonadotropin releasing hormone.
Biochem. Biophys. Res. Com., 55: 623 (1973)

20. Krause, W., Schwaebe, P.: FSH and testosterone levels in the plasma of juvenile male rats after application of ovine FSH, HCG, and PMS at different ages. Endokrinologie, 68: 22 (1976).

21. Lostroh, A. J.: Effect of follicle-stimulating hormone and interstitial cell-stimulating hormone on spermatogenesis in Long-Evans rats hypophysectomized for six months. Acta Endocrinol., 43: 592 (1963).

22. Lostroh, A. J.: Regulation by FSH and ICSH(LH) of reproductive function in the immature rat. Endocrinology, 85: 438 (1969).

23. Maraud, R., Couland, H., and Stoll, R.: Role inhibiteur de-l'hypophyse sur l'elaboration de l'inducteur testiculaire responsible de la regression des canaux de muller chez l'embryon de poulet. C. R. Soc. Biol., 160: 964 (1969).

24. Maraud, R., Stoll, R., and Couland, H.: Donnes nouvelles sur les role du testicule et de l'hypophyse dans la differenciation sexualle du poulet. C. R. Soc. Biol., 55: 442 (1970).

25. McKenzie, J.: The bioassay of thyrotropin in serum. Endocrinology, 63: 372 (1958).

26. Picon, R.: Action due testicule foetal sur le development in vitro des canaux de Muller le rat. Arch. Anat. Micro. Exp., 58: 1 (1969).

27. Picon, R.: Modification in the course of testicle development and its inhibitory action on the Müllerian ducts in vitro. C. R. Acad. Sci., 21: 2370 (1970).

28. Parlow, A.: A rapid bioassay method for LH and factors stimulating LH secretion. Federation Proc., 17: 402 (1958).

29. Steelman, S., Pohley, F.: Assay of the follicle stimulating hormone based on the augmentation with human chorionic gonadotropin. Endocrinology, 53: 604 (1953).

30. The authors thank Drs. John Crawford, Seymour Reichlin, Inese Beitins, Judith Vaitakaitis, and Jay Radhakrishnan for their helpful suggestions. We also thank Carmelo Bondi and Thomas Manganaro for technical assistance and Ms. B. J. Capistran for secretarial assistance. We are grateful to the NIAMDD Rat Pituitary Program of the National Institutes of Health for supplying the rat FSH.

31. Information supplied with FSH-RP-1 obtained from NIAMDD Rat Pituitary Program of the NIH.

32. This research was supported in part, by United States Public Health Service Grants AM-07039-02 and CA 17393-02.

33. Dr. Bercu is a Special Fellow, United States Public Health Service, New England Medical Center, and Research and Clinical Fellow, Massachusetts General Hospital.

34. Requests for reprints should be addressed to: Dr. Barry B. Bercu, Building 10, Room 8 D 47, National Institutes of Health, 9000 Rockville Pike, Bethesda, Md 20014 (USA).

35. Received for publication December 12, 1977.

36. Accepted for publication May 11, 1978. 